\title{
Paraneoplastic Thromboembolism and Thrombophilia: Significance in Visceral Medicine
}

\author{
Christian Pfrepper \\ Division of Hemostaseology, Medical Department I, University Hospital Leipzig, Leipzig, Germany
}

\section{Keywords}

Venous thromboembolism · Gastrointestinal cancer · Splanchnic vein thrombosis - Direct oral anticoagulants . Cancer-associated thrombosis

\begin{abstract}
Background: Venous (VTE) and arterial thromboembolism (ATE) are frequent complications of cancer. Risk assessment models (RAM) for stratification of the thrombotic risk in patients with gastrointestinal (GI) cancer have several limitations. Summary: While pancreatic and stomach cancer are considered very high risk in all RAM, the risk of colorectal cancer differs between RAM, and esophageal cancer and cholangiocarcinoma were underrepresented or not included in any RAM. In addition, up to $49 \%$ of patients with pancreatic cancer develop splanchnic vein thrombosis (SVT). Prophylaxis with low-molecular-weight heparins (LMWH) in ambulatory cancer patients is associated with a positive riskbenefit ratio only in high-risk patients and LMWH have been the standard of care for the treatment of cancer-associated VTE and SVT over the last years. Direct oral anticoagulants (DOAC) have been shown to be equally effective compared to $\mathrm{LMWH}$, but bleedings from the GI tract are more frequent. Therefore, recent guidelines suggest the use of DOAC for VTE treatment and for prophylaxis in ambulatory patients at high risk for VTE, but patients at high risk for bleeding, especially with active luminal cancer, should receive LMWH. Key Messages: This review discusses RAM and the current options for prophylaxis and treatment of cancer-associated ATE, VTE, and SVT focusing on Gl cancers. $\odot 2020$ The Author(s)

Published by S. Karger AG, Basel
\end{abstract}

\section{Introduction}

Armand Trousseau [1] first proposed the association between idiopathic thrombosis and occult malignancy in 1865 , shortly before he developed thrombosis himself and later died from gastric cancer (GC). In his 95th lecture on clinical medicine delivered at the Hôtel Dieu in Paris, he wrote: "I have long been struck with the frequency with which cancerous patients are affected with painful oedema in the superior or inferior extremities, whether one or other was the seat of cancer. [...] I have since that period had an opportunity of observing other cases of painful oedema, in which, at the autopsy, I found visceral cancer, but in which during life, there was no appreciable cancerous tumor; and in which there existed a cachexia referable neither to the tubercular diathesis, the puerperal state, nor chlorosis" [1]. Later, Rudolf Virchow described the multifactorial pathogenesis of thromboembolic events, commonly known as the Virchow triad, consisting of hypercoagulability, endothelial injury, and reduced blood flow [2].

\section{Risk Assessment Models for the Prediction of Thrombosis in Cancer Patients}

Nowadays we know that venous thromboembolism (VTE) is a frequent complication of cancer and accounts for around $9 \%$ of deaths in cancer patients [3]. Cancer patients have an up to 7-fold increased risk of VTE compared to the general population, with an annual VTE incidence ranging from 0.5 to $20 \%$ [4]. Several risk assess- (c) 2020 The Author(s) Published by S. Karger AG, Basel Karger Open access This is an Open Access article licensed under the Creative Commons Attribution-NonCommercial-4.0 International License (CC BY-NC) (http://www.karger.com/Services/OpenAccessLicense), applicable to the online version of the article only. Usage and distribution for con-
Christian Pfrepper

Division of Hemostaseology, University Hospital Leipzig

Liebigstrasse 20

DE-04103 Leipzig (Germany)

christian.pfrepper@medizin.uni-leipzig.de 


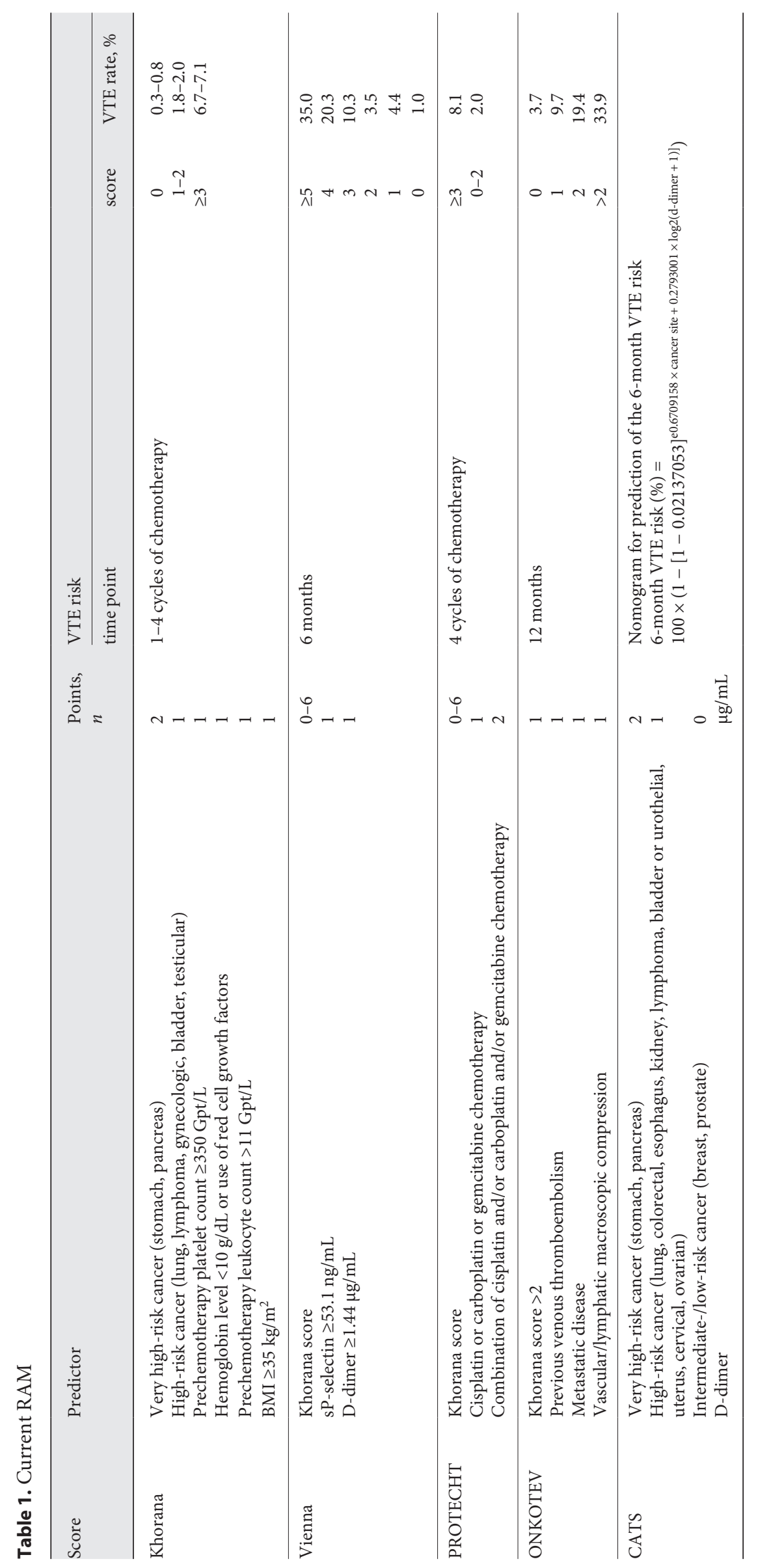


ment models (RAM) have been developed for stratification of the VTE risk in cancer patients, including clinical and laboratory parameters. In 2008 Khorana et al. [5] described the first risk score for the development of VTE in cancer patients. Pancreatic and stomach cancer were considered as very high-risk tumors, with an OR of 4.3 for development of VTE compared to low-risk tumors such as breast, colorectal (CRC), and head-and-neck cancer. In addition, a high platelet count, low hemoglobin, leukocytosis, and a body mass index (BMI) $>35 \mathrm{~kg} / \mathrm{m}^{2}$ were predictors of VTE. The score derived from the Vienna Cancer and Thrombosis Study (CATS) further refined the Khorana score by incorporating soluble P-selectin and $\mathrm{D}$-dimer into the prediction model [6]. Derived from a prospective study comparing nadroparin with placebo in metastatic or locally advanced cancer patients receiving chemotherapy [7], the PROTECHT score added points for gemcitabine- or platin-based chemotherapy to the Khorana score [8]. Several years later, the ONKOTEV score included metastatic disease and vascular/lymphatic compression by the tumor as well as a history of VTE, which were equally weighted as a Khorana score $>2$ [9]. More recently, a simple and easy-to-perform RAM was introduced by Ingrid Pabinger et al. [10] based on the CATS data and it was validated using a multinational cohort of cancer patients. This so-called CATS score only includes the tumor site category (low or intermediate vs. high vs. very high risk) and D-dimer as the most predictive biomarker for calculation of the 6-month incidence of VTE in cancer. Current RAM are summarized in Table 1.

\section{VTE Risk in Different GI Tract Cancers}

Focusing on the gastrointestinal (GI) tract, the highest risk entities in all RAM are GC and pancreatic cancer. Reported rates of VTE in patients with pancreatic cancer are variable, ranging between $10 \%$ within 3 months after initiation of chemotherapy in a prospective study [11] and $20-40 \%$ in different retrospective cohort studies [1216]. In a subgroup analysis from the ONKOTEV study, $49 \%$ of the patients with VTE had pulmonary embolism or deep vein thrombosis, while splanchnic vein thrombosis (SVT) accounted for $51 \%$ of cases $(21.6 \%$ splenic vein, $17.6 \%$ portal vein, and $11.8 \%$ other abdominal veins) [16]. In contrast, the incidence of VTE in GC and esophageal cancer (EC) ranges between 9 and 20\% [12, 17-21]. In a recent meta-analysis comparing GC and $\mathrm{EC}$, the incidence of VTE was higher in GC patients (17.8 vs. 13.4\%) and stage III/IV disease and neoadjuvant chemotherapy were identified as risk factors [20]. The VTE incidence of $\mathrm{CRC}$ is within the range of $\mathrm{EC}$ and ranges between 10 and $12 \%$ in North American cohorts $[12,19]$, but it was $17 \%$ in an Asian population and higher than the VTE rate of GC in that cohort [17]. The fact that some entities like EC are underrepresented in most RAM, others like CRC are counted as high risk in the CATS score but as low risk in the Khorana score, and some entities like cholangiocarcinoma (CC) are not included in any RAM shows the limitations of the existing RAM. This has been pointed out in a recent comparative analysis [22].

Apart from the limitations of all RAM, the CATS score is the easiest model to use in the clinical routine and provides an individual risk for every patient based on the tumor type and D-dimer. However, for the decision of whether primary prophylaxis should be offered, individual aspects like metastasis, vascular compression by the tumor and the patient's preference should be considered.

\section{Portal and SVT}

SVT includes portal vein thrombosis (PVT), mesenteric and splenic vein thrombosis, and Budd-Chiari syndrome (BCS). The portal vein system is a low-pressure system with high blood volumes slowly flowing through a unique vascular system. PVT is the most frequent type of SVT, with an incidence of 3.7 cases per 100,000 personyears [23]. Risk factors are heterogeneous and multifactorial and differ significantly between cohorts. The most common risk factors for PVT are portal hypertension due to liver cirrhosis (15-25\%), solid malignancy (10-25\%), myeloproliferative neoplasm (MPN; 11-20\%), local factors such as intra-abdominal infection and surgery (15$20 \%$ ), estrogen-containing contraceptives or hormone replacement therapy (11-15\%), and hereditary thrombophilia (15-22\%) [23-27]. The underlying disorders in a cohort of 163 patients with primary BCS were MPN (49\%), antiphospholipid syndrome (25\%) and paroxysmal nocturnal hemoglobinuria (19\%) [28]. The prevalence of MPN in a meta-analysis including 615 patients with PVT without liver cirrhosis or hepatobiliary cancer and 440 patients with primary BCS in whom a complete MPN work-up was performed was 31.5 and $40.9 \%$, respectively [29]. MPN subtypes include polycythemia vera (PV), essential thrombocythemia, primary myelofibrosis, and unclassifiable MPN. The prevalence of PV and primary myelofibrosis is higher in patients with BCS than in PVT patients [29]. The JAK2V617F mutation can be found in about $86 \%$ of patients with MPN presenting with PVT and in $80 \%$ of patients with primary BCS $[29,30]$. JAK2V617F mutation induces inflammation, integrininduced adhesiveness, tissue factor-containing microparticles, activation of procoagulant factors, and the formation of neutrophil extracellular traps causing an increased risk of thrombosis [31, 32]. The JAK2V617F mutation is more frequent in patients with MPN presenting with SVT 
compared to MPN patients without SVT [33]. A recently published risk model for the development of thrombosis in patients with JAK2V617F-mutated MPN identified age, $\geq 60$ years, hematocrit $\geq 48 \%$, at least 1 cardiovascular risk factor, a history of thrombosis, and an JAK2V617F allele burden $\geq 50 \%$ as multivariate risk factors. High-risk patients ( $\geq 2$ points) have an incidence of thrombosis of $72.9 \%$, while it was found to be only $9.1 \%$ in low risk patients ( 0 points) [34]. The more recently identified calreticulin (CALR) mutation is less frequent in MPN patients but it is found in up to $34 \%$ of JAK2V617F-negative patients with SVT [35]. Due to the high prevalence of MPN in SVT, the JAK2V617F mutation should be excluded in patients without liver cirrhosis and hepatobiliary cancer and the CALR-mutation should be excluded in JAK2V617F-negative patients. In addition, patients with SVT and especially those with BCS should be screened for paroxysmal nocturnal hemoglobinuria [36]. Besides the high risk of thrombosis, MPN patients may exhibit a high risk of bleeding due to platelet dysfunction, acquired von Willebrand syndrome, thrombocytopenia, and alterations of secondary hemostasis due to anticoagulation and acquired coagulopathies due to liver dysfunction $[37,38]$, making the treatment of these patients even more demanding.

\section{Arterial Thromboembolism}

Although the global incidence and mortality of arterial thromboembolism (ATE) in the general population is higher compared to that of venous thrombotic events [39], the epidemiology and risk factors for ATE in cancer patients are much less in the focus of research. In the Vienna CATS, which followed 1,880 cancer patients for a median of 2 years, the frequency of ATE was $2.6 \%$, while VTE was detected in $8.4 \%$ of patients. Myocardial infarction was the most frequent type of ATE (41.7\%), followed by stroke (33.3\%) and peripheral arterial events $(25.0 \%)$. The occurrence of ATE was associated with a 3.2-fold increased risk of mortality. Independent risk factors for ATE in this cohort of cancer patients were comparable with ATE risk factors of the general population: age, male sex, hypertension, and smoking. Lung and kidney cancer patients were at a higher risk for developing ATE, but only kidney cancer prevailed in multivariate analysis [40]. Zöller et al. [41] reported a 2-fold increased risk of coronary heart disease during the first 6 months after diagnosis of one of the following cancer types: stomach, small intestine, anus, liver, pancreas, lung, kidney, nervous system, endocrine glands, non-Hodgkin lymphoma, myeloma, and leukemia [41]. In a more recent matched pair analysis of Medicare data the highest incidence of ATE during the first 6 months was reported in lung cancer patients, with an HR of 3.6 and a cumulative incidence of $8.3 \%$, followed by pancreas $(\mathrm{HR}=3.0)$ and stomach $(\mathrm{HR}=3.0)$ cancer [42]. The risk of developing an ATE increases within the first year before the diagnosis of cancer [43], and it is highest at diagnosis and within the first 3 months after the diagnosis of cancer and decreases over time $[42,44]$. Beyond that, cancer-directed treatment can contribute to the ATE risk. Among those, platinum compounds, and particularly cisplatin, appear to increase the risk of ATE events [45].

\section{Prophylaxis of Cancer-Associated VTE}

Low-molecular-weight heparins (LMWH) are the standard treatment for the prophylaxis of hospitalized medical and surgical patients with cancer without contraindications for the use of anticoagulants. In hospitalized cancer patients without reduced mobility thromboprophylaxis can be omitted on an individual basis. In surgical cancer patients, the duration of thromboprophylaxis is according to the extent of the surgical procedure. While patients undergoing major cancer surgery involving the abdomen and pelvis, particularly those with additional risk factors, should receive an extended thromboprophylaxis for 28 days, prophylaxis can be limited to 6-10 days in patients with minor surgeries [46-49].

More concerns exist regarding thromboprophylaxis in outpatient cancer patients receiving chemotherapy. In a systematic review and meta-analysis, LMWH has been shown to significantly reduce the rate of symptomatic VTE (RR $=0.54$; 95\% CI 0.38-0.75) but with a trend toward an increased risk of major bleeding events ( $R R=$ 1.44; 95 CI 0.98-2.11). However, in unselected patients with a low thromboembolic risk according to the Khorana score, the event rate in the control group was low and the absolute risk reduction was only $2-3 \%$ [50]. Recently, 2 prospective studies evaluated the efficacy and safety of direct oral anticoagulants (DOAC) for thromboprophylaxis in patients with a Khorana score $\geq 2$. The AVERT trial compared $2 \times 2.5 \mathrm{mg}$ apixaban and the CASSINI trial $1 \times 10 \mathrm{mg}$ rivaroxaban with placebo [51, 52]. In the AVERT trial, apixaban significantly decreased the rate of VTE in the intention-to-treat analysis ( $4.2 \%$ on apixaban vs. $10.2 \%$ on placebo), but with a higher incidence of major bleedings (3.5\% on apixaban vs. $1.8 \%$ on placebo), mainly due to higher rates of GI bleeding, hematuria, and gynecologic bleeding in patients with GI and gynecologic cancers. In the CASSINI trial, all patients received a lower extremity ultrasound work-up at baseline and after 8, 16 , and 24 weeks, and patients with DVT at baseline were excluded $(49 / 1,080 ; 4.5 \%)$. The incidence of VTE was lower during the intervention period ( $2.6 \%$ on rivaroxaban vs. $6.4 \%$ on placebo) but not in the intention-to-treat 


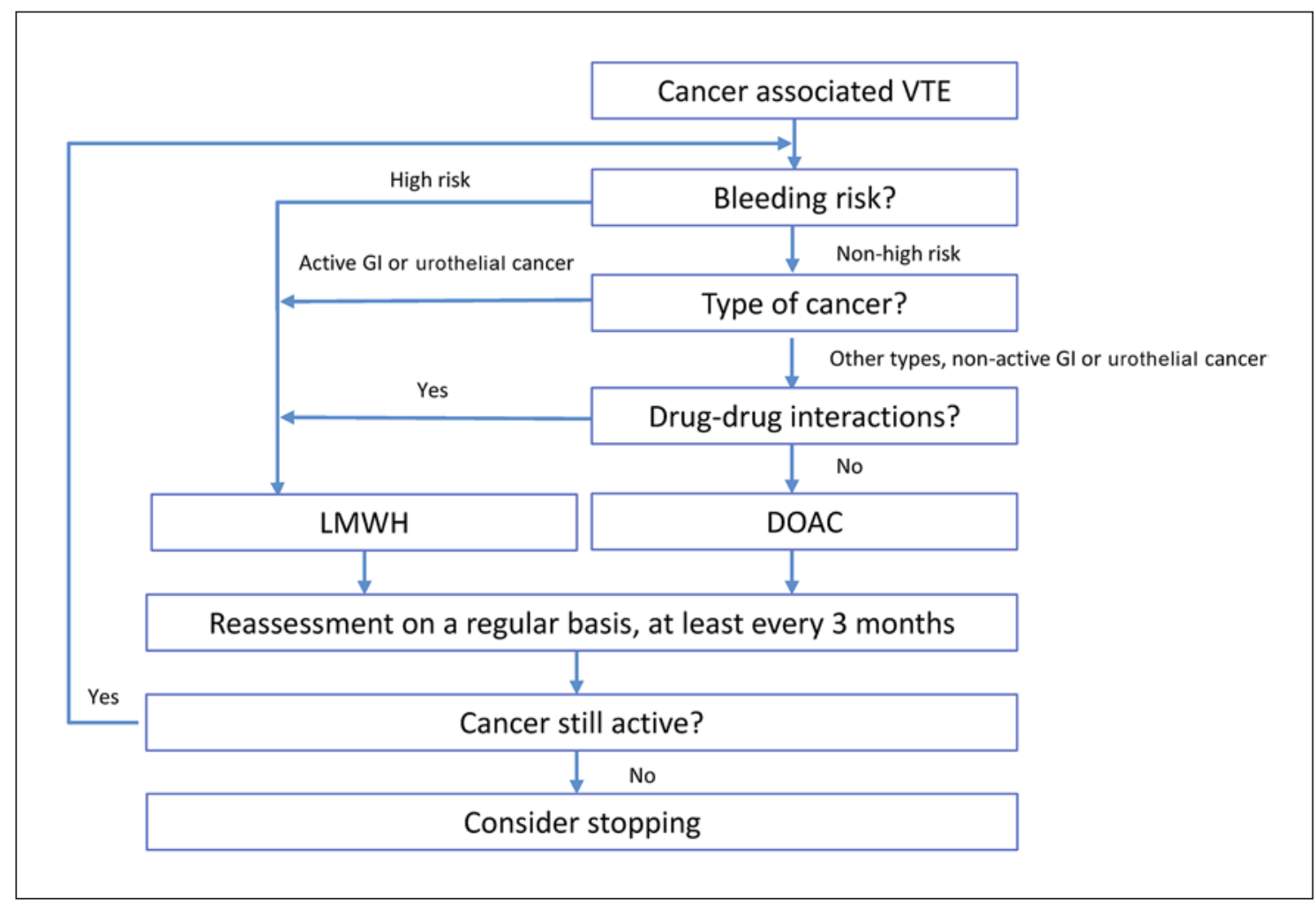

Fig. 1. Treatment algorithm for cancer-associated VTE based on Carrier et al. [64].

analysis. Rivaroxaban-treated patients had a nonsignificant increased risk of major bleeding (2.0\% on rivaroxaban vs. $1.0 \%$ on placebo) - again, with most bleedings being GI. A pooled analysis of both trials showed a significant reduction in VTE with a numerically increased risk of major and clinically relevant nonmajor bleedings (CRNMB) [53] for DOAC compared to placebo. Based on these studies, the International Society of Thrombosis and Hemostasis (ISTH) suggested the use of DOAC as primary thromboprophylaxis in ambulatory cancer patients with a Khorana score $\geq 2$ without drug-drug interactions and not at a high risk for bleedings. In patients with a high risk of bleedings (such as patients with gastroesophageal cancer) and planned thromboprophylaxis, LMWH should be used [53]. The ASCO guideline states that apixaban, rivaroxaban, or LMWH may be offered to patients with a Khorana score $\geq 2$ based on the bleeding risk, drug-drug interactions, and an individual discussion about harms and benefits [47]. Notably, the 2019 update of the International Initiative on Thrombosis and Cancer (ITAC) recommends the prophylactic use of DOAC in ambulatory cancer patients who are receiving systemic therapy and have an intermediate-high risk of VTE, identified by cancer type (i.e., pancreatic) or by a validated RAM (i.e., Khorana score $\geq 2$ ) and not actively bleeding or not at a high risk for bleeding [49]. However, it should be noted that apixaban and rivaroxaban are only ap- proved for thromboprophylaxis in patients undergoing total knee and hip replacement and not for primary prophylaxis in medical or cancer patients. In addition, the use of the Khorana score for prediction of VTE risk has several limitations. The CANTARISK trial showed that the Khorana score poorly performs in patients with lung cancer [54] and as, mentioned earlier, the risk of CRC is considered low risk in the Khorana score but high risk in the CATS cohort $[5,10]$. Moreover, some rare tumor entities like CC were not included in the existing RAMs.

\section{Treatment of Cancer-Associated VTE}

The treatment of cancer-associated VTE has changed within the last years significantly. Until 2018, LMWH was the standard of care for the treatment of cancer-associated VTE based on the results of the CLOT and the CATCH trials $[55,56]$. The treatment of cancer-associated VTE with DOAC was analyzed in 3 clinical trials. The Hokusai VTE Cancer Study [57] investigated edoxaban, the Caravaggio study apixaban [58] and the smaller SELECT-Dstudy rivaroxaban [59]. All of the trials found that DOAC treatment was noninferior for the prevention of recurrent VTE but none of the 3 DOAC was superior compared to dalteparin. The risk of major bleeding was higher with edoxaban than with dalteparin $(6.9$ vs. $4.0 \%, p=0.04)$. A 
subgroup analysis revealed that only patients with active GI cancer had a higher risk of major bleeding with edoxaban [60]. The cumulative incidence of major bleeding in the SELECT-D study was comparable in both groups, but the risk of CRNMB was higher with rivaroxaban (13 vs. $4 \%, \mathrm{HR}=3.76 ; 95 \%$ CI 1.63-8.69). Sites of bleeding under rivaroxaban were again located in the GI and genitourinary tract. In the Caravaggio study, the risk of major bleeding and CRNMB was comparable (major bleeding 3.8 vs. $4.0 \%$ and CRNMB 9.0 vs. $6.0 \%$ for apixaban vs. dalteparin) and there was no difference in GI bleeding rates. Current guidelines recommend the use of DOAC for the initial treatment of VTE in patients without strong drug-drug interactions and who do not have a high risk of GI or genitourinary tract bleeding. Especially in patients with active upper GI tract malignancies, DOAC should be avoided and LMWH should be prescribed [47, $49,61]$. It should be noted, that these guidelines do not yet include the data of the more recently published Caravaggio study regarding the comparable bleeding incidence with apixaban compared with LMWH. In addition, real-life data about the safety and efficacy of DOAC for the initial treatment of cancer-associated VTE are scarce. Anticoagulation beyond the initial 6 months should be offered to patients with active cancer with regular reassessment of the risk-benefit profile. In contrast to noncancer patients $[62,63]$, there is currently no evidence for the safety of dose-reduced DOAC for extended treatment of VTE. Figure 1 summarizes a current algorithm for cancer-associated VTE [64].

Less robust recommendations are available for the medical treatment of SVT in cancer patients, since guidelines focusing on cancer-associated VTE do not refer to SVT $[47,49]$ and guidelines focusing on vascular diseases of the liver do not include special recommendations for cancer patients [36]. Therefore, the available guidelines have adopted recommendations for nonmalignant SVT and evidence on cancer-associated VTE for patients with cancer-associated SVT, which may not be an appropriate approach [65]. An early start of anticoagulation has been shown to be associated with better recanalization in SVT patients [66, 67], but esophageal varices should be excluded before the initiation of a therapeutic dose. However, a prophylactic or intermediate dose can be considered when patients require multiple sessions of endoscopic band ligation [65]. LMWH are considered the standard of care for patients with malignant SVT because of their short half-life, the possible dose reduction in case of thrombocytopenia, and their superior effect compared to vitamin $\mathrm{K}$ antagonists in patients with cancer-associated VTE [65]. There are limited but somehow promising data regarding the efficacy and safety of DOAC in patients with nonmalignant SVT. A retrospective analysis showed a significantly higher complete recanalization rate in pa- tients treated with edoxaban compared to warfarin (70 vs. $20 \% ; p<0.001$ ) [68]. In a recent prospective study $2 \times$ $10 \mathrm{mg}$ rivaroxaban was associated with a better recanalization rate ( 90 vs. $45 \%$; $p=0.001$ ), fewer GI bleedings ( 0 vs. $43.3 \% ; p=0.001$ ), a lower MELD score (7.5 vs. $24 ; p<$ 0.001 ), and a better overall survival than warfarin [69]. However, more prospective data are needed to define the role of DOAC in the treatment of SVT in patients with and without cancer.

\section{Conclusion}

Patients with GI tract tumors are at a high risk for VTE and ATE, and especially in patients with pancreatic cancer SVT is a frequent complication. MPN should be ruled out in patients with idiopathic SVT. Prophylaxis in outpatients undergoing chemotherapy should be considered for patients with a high risk of VTE based on the cancer type and validated RAM, but the decision should be made on an individual basis taking into account the risk of bleeding and patients preferences. It can be anticipated that DOAC will play an emerging role for the prophylaxis and treatment of cancer-associated VTE in the near future. However, DOAC should be avoided in patients with a high risk of GI bleeding, particularly those with active luminal cancer. Real-life data comparing different types of tumors and anticoagulants will help to further define the role of DOAC in cancer-associated VTE.

\section{Conflict of Interest Statement}

Christian Pfrepper has received speaker honoraria from BMS, Pfizer, Roche, Shire, Bayer HealthCare, and CSL Behring and has been a medical advisor for CSL Behring, Bayer HealthCare, Roche, Chugai, Shire, Novo Nordisk, and Pfizer during the last 3 years.

\section{Funding Sources}

There was no funding in relation to the publication.

\section{References}

1 Trousseau A. Lecture XCV: phlegmasia alba dolens. In: Lectures on Clinical Medicine, delivered at the Hôtel-Dieu, Paris, translated from the third edition of 1868 by Sir J.R. Cormack. London: The New Sydenham Society; 1872. p. 281-332.

2 Dickson B. Venous thrombosis: on the history of Virchow's triad. Univ Toronto Med J. 2004;81:3.

3 Khorana AA, Francis CW, Culakova E, Kuderer NM, Lyman GH. Thromboembolism is a leading cause of death in cancer patients receiving outpatient chemotherapy. J Thromb Haemost. 2007 Mar;5(3):632-4. 
4 Horsted F, West J, Grainge MJ. Risk of venous thromboembolism in patients with cancer: a systematic review and meta-analysis. PLoS Med. 2012;9(7):e1001275.

5 Khorana AA, Kuderer NM, Culakova E, Lyman GH, Francis CW. Development and validation of a predictive model for chemotherapy-associated thrombosis. Blood. 2008 May; 111(10):4902-7.

6 Ay C, Dunkler D, Marosi C, Chiriac AL, Vormittag R, Simanek R, et al. Prediction of venous thromboembolism in cancer patients. Blood. 2010 Dec;116(24):5377-82.

7 Agnelli G, Gussoni G, Bianchini C, Verso M, Mandalà M, Cavanna L, et al.; PROTECHT Investigators: Nadroparin for the prevention of thromboembolic events in ambulatory patients with metastatic or locally advanced solid cancer receiving chemotherapy: a randomised, placebo-controlled, double-blind study. Lancet Oncol. 2009 Oct;10(10):943-9.

8 Verso M, Agnelli G, Barni S, Gasparini G, LaBianca R. A modified Khorana risk assessment score for venous thromboembolism in cancer patients receiving chemotherapy: the Protecht score. Intern Emerg Med. 2012 Jun; 7(3):291-2.

9 Cella CA, Di Minno G, Carlomagno C, Arcopinto M, Cerbone AM, Matano E, et al. Preventing Venous Thromboembolism in Ambulatory Cancer Patients: the ONKOTEV Study. Oncologist. 2017 May;22(5):601-8.

10 Pabinger I, van Es N, Heinze G, Posch F, Riedl J, Reitter EM, et al. A clinical prediction model for cancer-associated venous thromboembolism: a development and validation study in two independent prospective cohorts. Lancet Haematol. 2018 Jul;5(7):e289-98.

11 Pelzer U, Opitz B, Deutschinoff G, Stauch M, Reitzig PC, Hahnfeld S, et al. Efficacy of Prophylactic Low-Molecular Weight Heparin for Ambulatory Patients With Advanced Pancreatic Cancer: Outcomes From the CONKO-004 Trial. J Clin Oncol. 2015 Jun;33(18):2028-34

12 Khorana AA, Dalal M, Lin J, Connolly GC. Incidence and predictors of venous thromboembolism (VTE) among ambulatory high-risk cancer patients undergoing chemotherapy in the United States. Cancer. 2013 Feb;119(3):648-55.

13 Menapace LA, Peterson DR, Berry A, Sousou T, Khorana AA. Symptomatic and incidental thromboembolism are both associated with mortality in pancreatic cancer. Thromb Haemost. 2011 Aug;106(2):371-8.

14 Epstein AS, Soff GA, Capanu M, Crosbie C, Shah MA, Kelsen DP, et al. Analysis of incidence and clinical outcomes in patients with thromboembolic events and invasive exocrine pancreatic cancer. Cancer. 2012 Jun 118(12):3053-61.

15 Kruger S, Haas M, Burkl C, Goehring P, Kleespies A, Roeder F, et al. Incidence, outcome and risk stratification tools for venous thromboembolism in advanced pancreatic cancer: retrospective cohort study. Thromb Res. 2017 Sep;157:9-15.

16 Godinho J, Casa-Nova M, Moreira-Pinto J, Simões P, Paralta Branco F, Leal-Costa L, et al. ONKOTEV score as a predictive tool for thromboembolic events in pancreatic cancer: a retrospective analysis. Oncologist. 2020 Feb; 25(2):e284-90.
17 Aonuma AO, Nakamura M, Sakamaki K, Murai $\mathrm{T}$, Matsuda $\mathrm{C}$, Itaya $\mathrm{K}$, et al. Incidence of cancer-associated thromboembolism in Japanese gastric and colorectal cancer patients receiving chemotherapy: a single-institutional retrospective cohort analysis (Sapporo CAT study). BMJ Open. 2019 Aug;9(8):e028563.

18 Fuentes HE, Paz LH, Wang Y, Oramas DM, Simons CR, Tafur AJ. Performance of Current Thromboembolism Risk Assessment Tools in Patients With Gastric Cancer and Validity After First Treatment. Clin Appl Thromb Hemost. 2018 Jul;24(5):790-6.

19 Lyman GH, Eckert L, Wang Y, Wang H, Cohen $\mathrm{A}$. Venous thromboembolism risk in patients with cancer receiving chemotherapy: a real-world analysis. Oncologist. 2013;18(12): 1321-9.

20 Marshall-Webb M, Bright T, Price T, Thompson SK, Watson DI. Venous thromboembolism in patients with esophageal or gastric cancer undergoing neoadjuvant chemotherapy. Dis Esophagus. 2017 Feb;30(2):1-7.

21 Starling N, Rao S, Cunningham D, Iveson T, Nicolson M, Coxon F, et al. Thromboembolism in patients with advanced gastroesophageal cancer treated with anthracycline, platinum, and fluoropyrimidine combination chemotherapy: a report from the UK National Cancer Research Institute Upper Gastrointestinal Clinical Studies Group. J Clin Oncol. 2009 Aug;27(23):3786-93.

22 Di Nisio M, van Es N, Rotunno L, Anzoletti N, Falcone L, De Tursi M, et al. Long-term performance of risk scores for venous thromboembolism in ambulatory cancer patients. J Thromb Thrombolysis. 2019 Jul;48(1):12533.

23 Rajani R, Björnsson E, Bergquist A, Danielsson A, Gustavsson A, Grip O, et al. The epidemiology and clinical features of portal vein thrombosis: a multicentre study. Aliment Pharmacol Ther. 2010 Nov;32(9):1154-62.

24 Plessier A, Darwish-Murad S, HernandezGuerra M, Consigny Y, Fabris F, Trebicka J, et al.; European Network for Vascular Disorders of the Liver (EN-Vie). Acute portal vein thrombosis unrelated to cirrhosis: a prospective multicenter follow-up study. Hepatology. 2010 Jan;51(1):210-8.

25 Thatipelli MR, McBane RD, Hodge DO, Wysokinski WE. Survival and recurrence in patients with splanchnic vein thromboses. Clin Gastroenterol Hepatol. 2010 Feb;8(2): 200-5.

26 Riva N, Ageno W, Poli D, Testa S, Rupoli S, Santoro R, et al.; Italian Federation of Anticoagulation Clinics (FCSA); Italian Federation of Anticoagulation Clinics FCSA. Safety of vitamin $\mathrm{K}$ antagonist treatment for splanchnic vein thrombosis: a multicenter cohort study. J Thromb Haemost. 2015 Jun;13(6):1019-27.

27 Ageno W, Riva N, Schulman S, Beyer-Westendorf J, Bang SM, Senzolo M, et al. Longterm Clinical Outcomes of Splanchnic Vein Thrombosis: Results of an International Registry. JAMA Intern Med. 2015 Sep;175(9): 1474-80

28 Darwish Murad S, Plessier A, HernandezGuerra M, Fabris F, Eapen CE, Bahr MJ, et al.; EN-Vie (European Network for Vascular Disorders of the Liver). Etiology, management, and outcome of the Budd-Chiari syndrome. Ann Intern Med. 2009 Aug;151(3):167-75.

29 Smalberg JH, Arends LR, Valla DC, Kiladjian JJ, Janssen HL, Leebeek FW. Myeloproliferative neoplasms in Budd-Chiari syndrome and portal vein thrombosis: a meta-analysis. Blood. 2012 Dec;120(25):4921-8.

30 Qi X, Yang Z, Bai M, Shi X, Han G, Fan D. Meta-analysis: the significance of screening for JAK2V617F mutation in Budd-Chiari syndrome and portal venous system thrombosis. Aliment Pharmacol Ther. 2011 May; 33(10):1087-103.

31 Kroll MH, Michaelis LC, Verstovsek S. Mechanisms of thrombogenesis in polycythemia vera. Blood Rev. 2015 Jul;29(4):215-21.

32 Wolach O, Sellar RS, Martinod K, Cherpokova $\mathrm{D}$, McConkey M, Chappell RJ, et al. Increased neutrophil extracellular trap formation promotes thrombosis in myeloproliferative neoplasms. Sci Transl Med. 2018 Apr;10(436):10.

33 Sant'Antonio E, Guglielmelli P, Pieri L, Primignani M, Randi ML, Santarossa C, et al. Splanchnic vein thromboses associated with myeloproliferative neoplasms: an international, retrospective study on 518 cases. Am J Hematol. 2020 Feb;95(2):156-66.

34 Zhang Y, Zhou Y, Wang Y, Teng G, Li D, Wang Y, et al. Thrombosis among 1537 patients with JAK2V617F -mutated myeloproliferative neoplasms: risk factors and development of a predictive model. Cancer Med. 2020 Mar;9(6):2096-105.

35 De Stefano V, Qi X, Betti S, Rossi E. Splanchnic vein thrombosis and myeloproliferative neoplasms: molecular-driven diagnosis and long-term treatment. Thromb Haemost. 2016 Jan;115(2):240-9.

36 European Association for the Study of the Liver. Electronic address: easloffice@easloffice.eu. EASL Clinical Practice Guidelines: vascular diseases of the liver. J Hepatol. 2016 Jan;64(1):179-202.

37 Appelmann I, Kreher S, Parmentier S, Wolf $\mathrm{HH}$, Bisping G, Kirschner M, et al. Diagnosis, prevention, and management of bleeding episodes in Philadelphia-negative myeloproliferative neoplasms: recommendations by the Hemostasis Working Party of the German Society of Hematology and Medical Oncology (DGHO) and the Society of Thrombosis and Hemostasis Research (GTH). Ann Hematol. 2016 Apr;95(5):707-18.

38 Kaifie A, Kirschner M, Wolf D, Maintz C, Hänel M, Gattermann N, et al.; Study Alliance Leukemia (SAL). Bleeding, thrombosis, and anticoagulation in myeloproliferative neoplasms (MPN): analysis from the German SAL-MPN-registry. J Hematol Oncol. 2016 Mar;9(1):18.

39 Wendelboe AM, Raskob GE. Global Burden of Thrombosis: epidemiologic Aspects. Circ Res. 2016 Apr;118(9):1340-7.

40 Grilz E, Königsbrügge O, Posch F, Schmidinger M, Pirker R, Lang IM, et al. Frequency, risk factors, and impact on mortality of arterial thromboembolism in patients with cancer. Haematologica. 2018 Sep;103(9):1549-56.

41 Zöller B, Ji J, Sundquist J, Sundquist K. Risk of coronary heart disease in patients with cancer: a nationwide follow-up study from Sweden. Eur J Cancer. 2012 Jan;48(1):121-8. 
42 Navi BB, Reiner AS, Kamel H, Iadecola C, Okin PM, Elkind MS, et al. Risk of Arterial Thromboembolism in Patients With Cancer. J Am Coll Cardiol. 2017 Aug;70(8):926-38.

43 Navi BB, Reiner AS, Kamel H, Iadecola C, Okin PM, Tagawa ST, et al. Arterial thromboembolic events preceding the diagnosis of cancer in older persons. Blood. 2019 Feb; 133(8):781-9.

44 Navi BB, Howard G, Howard VJ, Zhao H Judd SE, Elkind MS, et al. The risk of arterial thromboembolic events after cancer diagnosis. Res Pract Thromb Haemost. 2019 Jun; 3(4):639-51.

45 Proverbs-Singh T, Chiu SK, Liu Z, Seng S, Sonpavde G, Choueiri TK, et al. Arterial thromboembolism in cancer patients treated with cisplatin: a systematic review and metaanalysis. J Natl Cancer Inst. 2012 Dec;104(23): 1837-40.

46 Deutsche Gesellschaft fuer Haematologie und medizinische Onkologie. Leitlinie: venoese Thrombembolien (VTE) bei Tumorpatienten. Available from: https://www.onkopedia. com/de/onkopedia/guidelines/venoesethrombembolien-vte-bei-tumorpatienten/ @@guideline/html/index.html.

47 Key NS, Khorana AA, Kuderer NM, Bohlke K, Lee AY, Arcelus JI, et al. Venous Thromboembolism Prophylaxis and Treatment in Patients With Cancer: ASCO Clinical Practice Guideline Update. J Clin Oncol. 2020 Feb; 38(5):496-520

48 National Comprehensive Cancer Network. NCCN Clinical Practice Guideline: CancerAssociated Venous Thrombembolic Disease. Version 1.2019 - February 28, 2019. Plymouth Meeting: NCCN; 2019.

49 Farge D, Frere C, Connors JM, Ay C, Khorana $\mathrm{AA}, \mathrm{Munoz} \mathrm{A}$, et al.; International Initiative on Thrombosis and Cancer (ITAC) advisory panel. 2019 international clinical practice guidelines for the treatment and prophylaxis of venous thromboembolism in patients with cancer. Lancet Oncol. 2019 Oct;20(10):e56681.

50 Di Nisio M, Porreca E, Candeloro M, De Tursi M, Russi I, Rutjes AW. Primary prophylaxis for venous thromboembolism in ambulatory cancer patients receiving chemotherapy. Cochrane Database Syst Rev. 2016 Dec 12:CD008500.
51 Carrier M, Abou-Nassar K, Mallick R, Tagalakis V, Shivakumar S, Schattner A, et al.; AVERT Investigators. Apixaban to prevent venous thromboembolism in patients with cancer. N Engl J Med. 2019 Feb;380(8):711-9.

52 Khorana AA, Soff GA, Kakkar AK, VadhanRaj S, Riess H, Wun T, et al.; CASSINI Investigators. Rivaroxaban for thromboprophylaxis in high-risk ambulatory patients with cancer. N Engl J Med. 2019 Feb;380(8):720-8.

53 Wang TF, Zwicker JI, Ay C, Pabinger I, Falanga A, Antic D, et al. The use of direct oral anticoagulants for primary thromboprophylaxis in ambulatory cancer patients: guidance from the SSC of the ISTH. J Thromb Haemost. 2019 Oct;17(10):1772-8.

54 Kuderer NM, Poniewierski MS, Culakova E, Lyman GH, Khorana AA, Pabinger I, et al. Predictors of Venous Thromboembolism and Early Mortality in Lung Cancer: Results from a Global Prospective Study (CANTARISK). Oncologist. 2018 Feb;23(2):247-55.

55 Lee Agnes YY, Levine Mark N, Baker Ross I, Bowden C, Kakkar AK, Prins M, Rickles FR, Julian JA, Haley S, Kovacs MJ, Gent M: Lowmolecular-weight heparin versus a coumarin for the prevention of recurrent venous thromboembolism in patients with cancer. $\mathrm{N}$ Engl J Med. 2003;349(2):146-153

56 Lee AY, Kamphuisen PW, Meyer G, Bauersachs R, Janas MS, Jarner MF, et al.; CATCH Investigators. Tinzaparin vs Warfarin for Treatment of Acute Venous Thromboembolism in Patients With Active Cancer: A Randomized Clinical Trial. JAMA. 2015 Aug; 314(7):677-86.

57 Raskob GE, van Es N, Verhamme P, Carrier M, Di Nisio M, Garcia D, et al.; Hokusai VTE Cancer Investigators. Edoxaban for the treatment of cancer-associated venous thromboembolism. N Engl J Med. 2018 Feb;378(7): 615-24.

58 Agnelli G, Becattini C, Meyer G, Muñoz A, Huisman MV, Connors JM, et al.; Caravaggio Investigators. Apixaban for the Treatment of Venous Thromboembolism Associated with Cancer. N Engl J Med. 2020 Apr;382(17): 1599-607.

59 Young AM, Marshall A, Thirlwall J, Chapman O, Lokare A, Hill C, et al. Comparison of an oral factor Xa inhibitor with low molecular weight heparin in patients with cancer with venous thromboembolism: results of a randomized trial (SELECT-D). J Clin Oncol. 2018 Jul;36(20):2017-23.
60 Kraaijpoel N, Di Nisio M, Mulder FI, van Es N, Beyer-Westendorf J, Carrier M, et al. Clinical Impact of Bleeding in Cancer-Associated Venous Thromboembolism: Results from the Hokusai VTE Cancer Study. Thromb Haemost. 2018 Aug;118(8):1439-49.

61 Khorana AA, Noble S, Lee AY, Soff G, Meyer G, O'Connell C, et al. Role of direct oral anticoagulants in the treatment of cancer-associated venous thromboembolism: guidance from the SSC of the ISTH. J Thromb Haemost. 2018 Sep;16(9):1891-4.

62 Agnelli G, Buller HR, Cohen A, Curto M, Gallus AS, Johnson M, et al.; AMPLIFY-EXT Investigators. Apixaban for extended treatment of venous thromboembolism. N Engl J Med. 2013 Feb;368(8):699-708.

63 Weitz JI, Lensing AW, Prins MH, Bauersachs $\mathrm{R}$, Beyer-Westendorf J, Bounameaux $\mathrm{H}$, et al.; EINSTEIN CHOICE Investigators. Rivaroxaban or aspirin for extended treatment of venous thromboembolism. N Engl J Med. 2017 Mar;376(13):1211-22.

64 Carrier M, Blais N, Crowther M, Kavan P, Le Gal G, Moodley O, et al. Treatment algorithm in cancer-associated thrombosis: canadian expert consensus. Curr Oncol. 2018 Oct; 25(5):329-37.

65 Ageno W, Beyer-Westendorf J, Garcia DA, Lazo-Langner A, McBane RD, Paciaroni M. Guidance for the management of venous thrombosis in unusual sites. J Thromb Thrombolysis. 2016 Jan;41(1):129-43.

66 Turnes J, García-Pagán JC, González M, Aracil C, Calleja JL, Ripoll C, et al. Portal hypertension-related complications after acute portal vein thrombosis: impact of early anticoagulation. Clin Gastroenterol Hepatol. 2008 Dec;6(12):1412-7.

67 Delgado MG, Seijo S, Yepes I, Achécar L, Catalina MV, García-Criado A, et al. Efficacy and safety of anticoagulation on patients with cirrhosis and portal vein thrombosis. Clin Gastroenterol Hepatol. 2012 Jul;10(7):776-83.

68 Nagaoki Y, Aikata H, Daijyo K, Teraoka Y, Shinohara F, Nakamura Y, et al. Efficacy and safety of edoxaban for treatment of portal vein thrombosis following danaparoid sodium in patients with liver cirrhosis. Hepatol Res. 2018 Jan;48(1):51-8.

69 Hanafy AS, Abd-Elsalam S, Dawoud MM. Randomized controlled trial of rivaroxaban versus warfarin in the management of acute non-neoplastic portal vein thrombosis. Vascul Pharmacol. 2019 Feb;113:86-91. 